\title{
Quién más ama las cosas. Radicalismo democrático y libertad igualitaria en Francis van den Enden
}

\author{
Diego Tatián \\ Universidad Nacional de Córdoba
}



Si en la historia de la crítica Spinoza ha sido considerado con frecuencia un filósofo de la libertad - un filósofo para quien libertad y orden no son contradictorios sino que se hallan inscriptos uno en otro (como es explícito en el subtítulo del Tratado teológico político que expresa el núcleo de la obra ${ }^{1}$-, su maestro Francis van den Enden puede ser designado como un pensador de la igualdad, en una multiplicidad de sentidos. El presente texto buscará indagar en la fórmula "libertad igualitaria", que enuncia la tesis principal del libro - recientemente traducido al español ${ }^{3}$ - Proposiciones políticas libres y consideraciones acerca del Estado (Vrye Politijke Stellingen), cuya edición data de $1665^{4}$, y que habría sido redactado durante los mismos años en los que Spinoza trabajaba sobre la primera Ética. Asimismo, se buscará explicitar la presencia oculta del escrito vanendeniano en el Tratado político, por medio de una aproximación de citas que revelan nítidas sus marcas en el pensamiento último de Spinoza.

En 1662 Van den Enden había publicado un Breve relato de la Nueva Holanda, con el cual se proponía "solicitar en nombre de algunas pocas y tímidas personas a las antiguas cámaras co-

1 "Contiene varias disertaciones, en las que se demuestra que la libertad de filosofar no sólo se puede conceder sin perjuicio para la piedad y para la paz del Estado, sino que no se la puede abolir sin suprimir con ella la paz del Estado e incluso la piedad" (Spinoza, 1986b, p. 6o).

2 La expresión holandesa original (Even gelijkevryheit) encierra el pleonasmo Evengelijkheit, es decir "igualdad igualitaria", énfasis que marca la centralidad que el autor busca conferir a este concepto.

3 Franciscus van den Enden, Libertad política y Estado, versión y prólogo de Leandro García Ponzo.

4 Como el propio autor señala en el "Prefacio", se trata de la primera parte de la obra, en tanto que la publicación de la segunda -que estaría compuesta por dos textos ya concluidos al momento de esta edición- era anunciada allí mismo: "Tengo aquí, mi Lector, la obligación de ofrecerte la esperanza de una segunda parte sobre el mismo tema; ahora tú puedes probar, entonces, la primera parte de dos textos siguientes (que juntos constituirán la planeada segunda parte) y deliberar acerca de ella, hasta que el Editor, por experiencia del beneficio, sea alentado por ti para imprimir también las dos partes restantes, que están prácticamente terminadas desde el verano pasado" (Van den Eden, 2010, p. 38). Este manuscrito habría sido destruido durante el proceso del Caballero de Rohan, a resultas del cual Van den Enden fue condenado a morir en la horca el 27 de noviembre de 1674 al ser desmantelado el complot republicano contra Luis XIV del que formaba parte. 
loniales de este poblado una valiosa oportunidad para la Nueva Holanda" (Op. Cit., p. 37). Una de esas personas fue el mennonita Peter Cornelius Plockhoy van Zierikzee, quien en 1661 le había encomendado la redacción de unos Requerimientos dirigidos a las autoridades amstelodanas para el establecimiento de una pequeña cooperativa en Norteamérica, desde julio de 1663. Como Van den Enden, Plockhoy era un igualitarista radical que se había propuesto instaurar esa comunidad sobre la base de una fraternidad natural entre sus miembros y una irrestricta libertad de pensamiento. Los principios de ese asentamiento eran: trabajo colectivo, comunidad de bienes, abolición de todas las formas de jerarquía social, privilegios o relaciones de dominación, absoluta igualdad entre los sexos, a la vez que se declaraban ideas más generales como la supresión de la esclavitud y la defensa de los pueblos originarios norteamericanos. Muchas ideas de la utopía plockhoyana serán asumidas luego por las Proposiciones políticas libres (ver J. Israel, 2005, pp. 213-223).

Ya en su clásico estudio Spinoza et son cercle. Étude critique historique sur les hétérodoxes hollandais (1896), K. O. Meinsma - quien califica de "lucianista" a Van den Enden -, así como Madeleine (Madelaine, 1937) había destacado, contra la posición de Israel S. Révah, que tiende a desvincular los elementos herejes de Spinoza de cualquier inspiración no judía, la influencia intelectual del maestro libertino sobre el joven Baruch5. Más recientemente, Marc Bedjai (Bedjai, 1990a e 199ob) y Wim Klever (Klever, 1990) han acentuado de manera extrema la influencia de Van den Enden sobre Spinoza; según Klever (Van den Enden,

5 Según una muy discutida y arriesgada tesis, Meinsma afirma que la influencia se revierte y que fue Spinoza el responsable de las ideas radicales de su maestro de latín: “...el joven pensador, que ejercía una potente influencia sobre todos a quienes frecuentaba, condujo a Franciscus van den Enden al panteísmo: es el alumno el que convierte al maestro. En efecto, no es en torno a este último sino en torno del primero que se reúne el grupo panteísta; no es el maestro sino el alumno la fuente de la que brota la corriente panteísta" (Meinsma, 2006, p. 147). 
1992 $)^{6}$ descubiertas en la Biblioteca Nacional de París por Bedjaï) todos los temas centrales del spinozismo se encuentran ya en la obra de su instructor. Los escritos políticos vanendenianos deberían así, según su editor, ser considerados un tratado político radical y antiteológico en el que se sientan las bases para la fundación de un Estado libre, cuya clave es la libertad de expresión (Cf. Klever, 1993, p. 624). Spinoza no habría tomado de Van den Enden únicamente su radicalismo democrático sino también otros motivos no directamente políticos, centrales en el spinozismo, como la identidad de Dios y la naturaleza, el rechazo al dualismo cartesiano, la distinción del conocimiento en tres géneros, la tesis del paralelismo, así como la expresión "amor Dei intellectualis". Todo lo cual hace afirmar a Klever que "El descubrimiento de la obra del maestro de Spinoza parece ser el mayor acontecimiento en la historiografía del spinozismo"7 (Ibid., p. 631).

Mediante un cuidadoso trabajo textual y una muy completa evaluación de documentos recientes, Omero Proietti ha corroborado la participación de Spinoza -transmitida por varias fuentes como Lucas, Kortholt, Colerus y Bayle - en al menos cuatro representaciones teatrales montadas por los alumnos de Van den Enden en el teatro de Ámsterdam durante los años 1657 y 1658; esas piezas fueron: una obra de teatro teológico jesuita escrita por el propio Van den Enden llamada Philedonius; Andria y Eunucus de Terencio, y Las troyanas de Séneca. Sin embargo, Proietti considera una "secular mitología" la vieja interpretación que le

6 Recientemente también fue publicada la edición inglesa con un largo estudio introductorio de Klever: Franciscus Van den Enden, Free, Political propositions And Considerations of State (1665), Text in Traslation, the Relevant Biographical Documents and a Selection from Kort Verhael. Introduced, precented translated and commented by Wim Klever, Vrijstad, 2007.

7 Contra esta posición ha reaccionado Miquel Beltrán, quien radicaliza el judaísmo de Spinoza y ha llegado a afirmar que "el Dios de Spinoza, considerado en sí mismo, es idéntico al de Maimónides" y que "mi convencimiento de esta afinidad [entre Spinoza y sus predecesores judíos] es... mayor que el de cualquier estudioso que haya tratado la cuestión..." (Un espejo extraviado. Spinoza y la filosofía hispano-judía, Riopiedras, Barcelona, 1998, p. 63). 
atribuye a Van den Enden ser "la verdadera, secreta pero nunca comprobada fuente [de] toda tesis 'herética', 'atea' o 'libertina' no resultante de la biblioteca spinoziana”, mitología revitalizada en los años noventa del siglo XX por los trabajos de Bejdai y Klever y la atribución (no fehaciente, siempre según Proietti) a Van den Enden de las Vrye Politijke Stellingen y del Korte Verhael van Nieuw-Nederland (1662) (Cf. Proietti, 2010) ${ }^{8}$.

Sin dejar cerrada la discusión aquí planteada relativa a su autoría, Proposiciones políticas libres - adoptando en adelante su atribución a Van den Enden - fue concebido como un escrito de intervención, que en este caso no se dirige tanto a un virtual "filósofo lector" abierto al examen desprejuiciado de las ideas, según era invocado por Spinoza hacia el final del Prefacio al Tratado teológico político, sino al pueblo holandés con el propósito de evitar la "muerte servil de la libertad igualitaria", amenazada tanto desde el interior como desde el exterior (Van den Enden, 2010, pp. 39-40). Para lo cual, dice nuestro autor, resulta indispensable la constitución de una ciudadanía activa, sin cuyo apoyo los "débiles regentes holandeses" no podrán perseverar durante mucho tiempo. Jan de Witt, con quien Van den Enden mantuvo relación epistolar, era entonces Gran Pensionario de las provincias de Holanda desde 1653 tras la muerte de Guillermo II de Orange-Nassau.

El pensamiento radical-democrático cuyo foyer es el taller vanendeniano disputa con la perspectiva socioeconómica de los regentes y se inscribe en una discusión cuyo trasfondo inmediato era la publicación en 1660 de las Consideraciones políticas de Jo-

8 Marc Bedjaï propone una fuerte inspiración rosacruciana y hermético-alquímica de estos textos, y por tanto afirma allí la existencia de una descuidada fuente del spinozismo. En sentido opuesto a la interpretación de Proietti, el Philedonius es aquí considerado como un "escrito hermético" y Spinoza, quien había actuado en la representación de la obra- prolongaría en su filosofía la ruta hermético-alquímica legada por su maestro: "La Ética es la expresión rigurosa, formalizada y definitiva del sistema hermético de la Naturaleza fundado en la analogía microcosmos / macrocosmos... Ethica ordine hermetico alchymicoque demonstrata!" (Ver Bejdaï, 1990a e 199ob). 
han de la Court9 (tal vez el primer escritor en lengua holandesa en postular la comunidad popular democrática como "la forma de gobierno más natural y más razonable"); en efecto Van den Enden criticará la indiferencia de los Regentes por la cuestión social tanto como su oposición a un gobierno popular que el radicalismo de Ámsterdam buscaba impulsar. Esta coexistencia de prosperidad y pobreza era considerada el núcleo de la política económica llevada adelante por los Regentes, a quienes el viejo lucianista instaba a revisar y sobre todo a restituir el poder al pueblo para garantizar su propia estabilidad. Faltaban aún varios años para que Jean de Witt fuera linchado en las calles de La Haya junto a su hermano Cornelius en agosto de 1672 por una multitud instigada a ello desde el poder clerical ${ }^{10}$, perdiéndose de este modo la República y la posibilidad de una libertad igualitaria que las Vrye Politijke Stellingen buscaban fundamentar y defender.

La primera parte de este singular escrito de multívoca radicalidad, comienza postulando una tesis aparentemente antispinozista: "Por naturaleza todos los hombres (incluyendo ambos sexos) nacen libres...", y luego de trazar una genealogía naturalista de la sociedad (de cuño aristotélico), postula el origen civil de la violencia humana y de las pasiones que arrastran a los hombres contra sus semejantes, conforme una antropología claramente antihob-

9 Van den Enden menciona a Johan de la Court hacia el final del Prefacio, y, aunque sin nombrarlos, parece aludir a él y a su hermano Pieter en el siguiente pasaje: "Pero en nombre del único verdadero y valioso gobierno del pueblo, a mi criterio, hay en la lengua holandesa no más de dos [escritores políticos] que en esa dirección han osado afirmar y proponer algo abiertamente" (Van den Enden, 2010, p. 64).

10 Con singular providencia Van den Enden relata hacia el final del texto la historia del conde Diederik, célebre por su tiranía, contra quien los ciudadanos planearon una conspiración junto con los frisios. Con ayuda del Papa, Diederik y sus secuaces "sacaron en una noche a los más ricos y poderosos señores de Holanda y Vrieslant de sus camas y los hicieron decapitar, el día después, junto con algunos jefes de la comunidad, ante la vista de la multitud del pueblo". Y en una nota añadida a esta historia, agrega: "Esto significa: cuidado. Respecto de lo cual, en las circunstancias y coyunturas contemporáneas de los Tiempos no puede indicarse un mejor o más seguro consejo para los actuales escasos y débiles Regentes holandeses, que reforzarse incondicionalmente y de modo igualitario con la multitud de ciudadanos competentes" (Van den Enden, 2010, pp. 86-87). 
besiana que según Jonathan Israel era característica de los escritores inscriptos en la corriente de pensamiento designada como "Ilustración radical"1. Escribe Van den Enden:

Porque si sucediera de otro modo y el hombre fuera desde su primera naturaleza o carácter igual a un Lobo, etc: cruel, violento, rencoroso y consecuentemente insociable, se seguiría que debería ser y permanecer como tal durante toda su existencia. Y lo contrario es notorio para nosotros. Como no es menos notorio que todas las pasiones excesivas y despreciables de los humanos no se originan en nada más que en el hecho de que ellos son mantenidos en continua ignorancia por gobiernos violentos, variados artificios maliciosos o incluso artimañas supersticiosas de todo tipo y, por consiguiente, de una educación perniciosa. Además de la liberación y salvación del pueblo cuya práctica en estas condiciones será siempre y totalmente imposible... (Van den Enden, 2010, p. 49)

En sintonía con la tradición libertina, Van den Enden descubre siempre una "impostura" ${ }^{12}$ a la base de sociedades divididas en dominadores y dominados a las que contrapone la libertad igualitaria, cuya restitución dota a cada ser humano de la capacidad para ser miembro de la Asamblea popular, rehusando cualquier

11 Según Israel el estado de naturaleza spinozista diverge completamente del hobbesiano. Si éste es "un reino de tinieblas y terror que quienes viven el medio más seguro de la sociedad civil regida por un soberano no quieren volver a ver, para los radicales el 'hombre natural' permanece un concepto pertinente y crucial para describir la sociedad" (Les lumières radicales..., cit, pp. 315-319). En este caso, el cometido de la obra política no es proteger a los hombres de su naturaleza sino continuarla conforme una utilitas común - que no sólo no cancela sino incluso incrementa el derecho natural de cada uno - e instituir la forma política más próxima al estado natural, que según Spinoza y los autores radicales era la democracia.

12 La impostura, enseña Van den Enden, es siempre a la vez política y religiosa, por lo cual "en este mundo jamás se hallará ninguna tiranía sin la compañía de la impostura papal, y tampoco impostura papal alguna sin tiranía. Por ende, si queremos encontrarnos totalmente libres de la tiranía, tendremos que evitar en primer lugar toda impostura papal" (Ibid., p. 89). La crítica vanendeniana de la superstición como puro medio de dominación política y el concepto de una "religión verdadera" de estricto sentido práctico, reducida a la "práctica del bien común de todos los pueblos" y al credo mínimo de "amar a Dios y al prójimo" anticipa de manera nítida el planteo del Tratado teológico político que sería publicado pocos años después. 
procedimiento de autorización, delegación, transferencia o alienación en otro de su propia capacidad de juzgar, de pensar y de intervenir. La búsqueda del bienestar propio se inscribe en el "mutuo compañerismo", no es individual ni equivale a un autointerés puramente negativo y posesivo; se comprende y practica con otros en la Asamblea, donde nadie representa a nadie. Se trata de una común extensión de la libertad igualitaria en consonancia... con los requerimientos de la Naturaleza.

Vale decir que las instituciones políticas que presuponen y amparan la libertad igualitaria no implican ningún tipo de operación sacrificial ni una renuncia del bienestar, el juicio o el placer individuales sino su incremento. Cada individuo "sin excepción” ("hombres y mujeres", insiste Van den Enden una y otra vez) conserva plena su natural libertad igualitaria en la Asamblea democrática que, en cuanto tal, aloja todos los "deseos" y diferencias de "inclinación". El matrimonio mismo es considerado como una institución estrictamente política, contemplándose en un Estado libre el "absoluto divorcio" de ser necesario ${ }^{13}$. Más todavía: en un pasaje se extiende la "libertad igualitaria" a la sexualidad sugiriéndose la conveniencia del amor libre entre las personas, pues “... hay que dejar a cada padre y madre de familia su libertad natural para licenciarse entre sí tanto como se encuentren en condiciones de acordar y de aprobar en lo relativo a su bienestar familiar y a sus deberes conyugales y mutua satisfacción" (Ibid., p. 111). Cualquier retórica que busque presentar como contradictorios el bien común y el bien particular - que comienza por ser económico (Ibid., p. 55) - deberá ser considerada como una simple impostura orientada a promover el engaño, el miedo y el terror con el objeto de separar a los hombres de sus "pensamientos libertarios" y pre-

13 “...porque es contra toda razón y sensatez que dos personas, habiendo alcanzado conjuntamente el mutuo placer y asistencia se encuentren constreñidos a permanecer juntos para su mutuo pesar y a menudo también para su total ruina y la de su familia" (Ibid., pp. 111-112). 
cipitarlos en la esclavitud. Compañía y singularidad se articulan "con arreglo a la Naturaleza", al igual que la plenitud del cuerpo y la plenitud del alma - imposible una sin la otra.

En tanto expresión de la libertad igualitaria de hombres y mujeres, la Asamblea popular vanendeniana presupone algunos requisitos, entre los cuales:

- Conservación de la capacidad de juzgar acerca de los propios asuntos y de los asuntos comunes y jamás descansar sobre el juicio y la creencia de otro (Ibid., p. 51);

- Preservación del propio bienestar, pues esa Asamblea no presupone nada que vaya contra la Naturaleza y, por tanto, nada que exija el sacrificio de la propia plenitud; de manera que "tenemos motivo para considerar enemigos y para tratar de destruir a todos aquellos que intencionalmente tienden a privarnos y a alejarnos de nuestro bienestar" (Ibid., p. 52).

- Repulsión y rechazo de todos los males corporales que arrastran consigo a la criatura hacia la desgracia y la esclavitud, pues "siendo dominado e inhibido el cuerpo, todos son... incapaces de practicar su bienestar... en función del requerimiento de sus respectivas naturalezas" (Ibid.);

- Extensión de la política a la totalidad de los cuerpos existentes: "más o menos inteligentes, más o menos benignos, hombres y mujeres, padres e hijos, sirvientes y servidos, gobernantes y gobernados..." (Ibid., p. 54), los que se abocan al uso colectivo del pensamiento y a la experiencia común de la razón pública.

- Destitución y rechazo activo de todo lo que instituye jerarquías y escalas simbólicas entre los hombres, tales como "títulos de excelencia” o nombres de doctores o profesores, que establecen falsos privilegios y vanidades y destruyen la igualdad que la vida pública debe mantener cuando la tiene o restituir cuando la ha perdido. Esta observancia orientada a prevenir la (re)generación de jerarquías deberá adoptar un carácter institucional en tanto “estricta ley común" cuyo correlato en el arte y la ciencia es la deposición del principio de autoridad (ver Ibid., pp. 58-59). Se trata 
de un recaudo fundamental para la institución de la libertad igualitaria adoptado en los mismos términos en un pasaje del Tratado político - que hace constelación con otros en los que se considera a los "premios" como cosa de siervos y como un recurso derivado de una lógica de la trascendencia -, donde Spinoza alude a la "indignación de todos los hombres de bien" y a la ruptura de la igualdad que está en la base de la "libertad común" que conllevan los premios y los honores públicamente otorgados:

Por lo demás, las estatuas, los emblemas y otros incentivos de la virtud más bien son signos de esclavitud que de libertad, pues es a los esclavos y no a los hombres libres a quienes se otorgan premios por su virtud. Reconozco que sin duda los hombres se estimulan con estos alicientes. Pero así como, en un comienzo, estas distinciones se conceden a relevantes personalidades, así después, al crecer la envidia, las recibe gente inútil y engreída por sus muchas riquezas, con la consiguiente indignación de todos los hombres de bien... Finalmente... es cierto que la igualdad, cuya pérdida lleva consigo automática y necesariamente la pérdida de la común libertad, no puede, en modo alguno, ser considerada desde el momento en que el derecho público otorga a un hombre, eminente por su virtud, honores especiales (Spinoza, 1986a, X, 8).

La institución de la igualdad se extiende asimismo a una idea comunitaria de medicina, que Van den Enden propone sea "investigada, practicada y más segura y claramente enseñada de manera colectiva”, "con honesto apoyo del común” y a máxima distancia del lucro privado - al tiempo que se sugiere la gratuidad de los remedios. La práctica comunitaria del arte de curar es presentada como dimensión fundamental de la república igualitaria, sin que se deba "permitir jamás que ellos [los médicos], practicando la medicina de modo privado, perciban por ello la menor compensación... [sino] un salario honesto conducido por lo común...". Y todo acompañado por un trabajo radical sobre la lengua, que era central en el círculo spinozista de Ámsterdam: 
la medicina - al igual que el derecho, la teología, la filosofía... deberá adoptar la lengua vernácula para su apropiación popular y la anulación de todo privilegio establecido por el esoterismo en el que el latín mantiene a los saberes, fuera del alcance del pueblo. Por lo que, escribe Van den Enden, “todo deberá desarrollarse en medio de la lengua madre de esta misma República, bajo exclusión de viejos y obsoletos lenguajes de libro, de modo que cada uno de los ciudadanos pueda libremente oír y acceder..." (Van den Enden, 2010, pp. 59-60), lo cual presupone a su vez le esté garantizado a todos ("jóvenes y adultos", "tanto a hombres como a mujeres", "hijos e hijas", etc.), una educación "sin costos" gracias a la cual "aprendan a hablar, leer y escribir" (Ibid., p. 61) 14. $^{14}$

La Asamblea libre es el lugar de constitución de una lengua colectiva. Van den Enden argumenta a favor del gobierno popular (“...la democracia, el único verdadero y libre gobierno del pueblo...”) contra la larga tradición - de cuño aristotélico - que postula el régimen mixto como la mejor forma de gobierno. Y sobre todo contra el argumento de la presunta estupidez e ignorancia del pueblo; siempre será preferible la lentitud del común

14 Para los autores radicales de Ámsterdam que formaban el círculo spinozista, el contenido político de la filosofía no es independiente de su popularización. La construcción de una filosofía popular en lengua vernácula, protegida por el anonimato, el pseudónimo, la clandestinidad y orientada a la emancipación religiosa y política, testimonia una confianza en la potencia transformadora de las ideas que, sin apartarse nunca de un realismo estricto, incluye en la reflexión filosófica las condiciones sociales de su práctica. El trabajo contra la superstición comienza por una intervención sobre la lengua. Sin embargo, a diferencia de Van den Enden, Balling, Koerbagh o los hermanos De la Court, Spinoza no escribió su obra en lengua vernácula, seguramente por no dominarla lo suficiente como para hacerlo. Sus idiomas maternos, el español y el portugués, resultaban como es obvio inapropiados para escribir filosofía en Holanda, pues ello hubiera restringido aún más que el latín la popularización de su pensamiento. Hacia el final de la carta a Blijenbergh del 5 de enero de 1665 - se trata de la primera carta, redactada en holandés seguramente por ignorar la formación de su interlocutor -, confiesa Spinoza: "Mucho me gustaría poder escribir en la lengua en la que me he educado, porque quizás pudiera así expresar mejor mis pensamientos. Pero sírvase tomar esto a bien y corregir usted mismo las faltas" . La referencia a "la lengua en la que me he educado" puede aludir tanto al portugués como al español, e incluso al latín; como quiera que sea, el reconocimiento de esta dificultad con el holandés proporciona con claridad el motivo de no haber optado por él para la redacción filosófica. 
razonamiento y la orientación "mediante libres deliberaciones", en tanto que es necesario siempre desconfiar como de un impostor de quien intente "acusar al pueblo de estupidez para salvarlo" (Ibid., p. 70). La naturaleza es tal que jamás permite asegurar que los “supuestos hombres más inteligentes y mejores estarían siempre con honestidad comprometidos con el bien común por sobre su bien privado" (Ibid., pp. 72-73), o dicho con otros términos: la naturaleza es la misma para todos, por lo que el gobierno no deberá ser encomendado a la virtudes privadas sino a las instituciones públicas. Nadie persigue el bien común si ello implica el sacrificio del propio bienestar, habida cuenta de que "no hablo acerca de los santos", escribe con ironía nuestro autor, "quienes son difíciles de encontrar, más todavía de ser reconocidos entre las personas"15 (Ibid., p. 73). Por lo que, y no obstante las dificultades que se presentan en la construcción de un juicio colectivo, "el peligro menor se sitúa en las deliberaciones y resoluciones del pueblo", cuya práctica dispone a "vigilar, observar y trabajar" (Ibid., p. 76) para una extensión de la experiencia política. Se revela clara la sintonía de estas páginas vanendenianas con algunos pasajes del Tratado político, donde leemos por ejemplo que

mientras unos pocos lo deciden todo según su propio gusto, perece la libertad y el bien común. Porque los talentos humanos son demasiado cortos para poder comprenderlo todo al instante. Por el contrario, se agudizan consultando, escuchando y discutiendo (sed consulendo, audiendo et disputando acuuntur) y, a fuerza de ensayar todos los medios dan, finalmente, con lo que buscan y todos aprueban aquello en que nadie había pensado antes. (De esto hemos visto muchos ejemplos en Holanda)" (Spinoza, 1986a, pp. 208-209).

15 Tal vez sea posible considerar esta línea como otra cita oculta en el comienzo del Tratado político: "Por eso [los filósofos] suelen reírse o quejarse de ellos [los hombres], criticarlos o (quienes quieren aparecer más santos [qui sacntiores videri volunt]) detestarlos" (Spinoza, 1986a, I, \$1). 
No es mediante la superstición y la ignorancia que se preserva al pueblo del desorden; antes bien por el contrario, en una Asamblea libre "el más sabio o el más inteligente siempre gobernarán, pero jamás podrá decirse quiénes son" (Van den Enden, 2010). Es la Asamblea misma la fragua de los gobernantes, que no se determinan en virtud de requisitos previos a la experiencia deliberativa, tales como el linaje, la pertenencia social, la educación o la riqueza. El pueblo de Van den Enden está pues formado por todos, por cualquiera. Resignificación fundamental que hallamos, asimismo, en el Tratado político.

En una contribución de Marilena Chaui sobre "La plebe y el vulgo en el Tractatus politicus" (Chaui, 1990, pp. 69-95) en el que analiza el texto de Tratado político, VII, $27^{16}$, se marca la radical innovación del fragmento spinozista no sólo por relación a la tradición clásica inspirada en Tito Livio, sino también con respecto a un conjunto de escritos que promueven el derecho de resistencia, tales como el Acta de destitución de 1581 (por el cual los Estados Generales de los Países Bajos recusan obediencia y fidelidad al rey de España, calificado allí de tirano), un texto anónimo contemporáneo de similar tenor conocido como Documento de Antuerpia, la llamada Deducción de Vrancken (1587) o las Vindiciae contra Tyrannos (1579). En todos estos casos, el "pueblo" invocado como sujeto político que ha de derribar al tirano está constituido

${ }_{16}$ "Pero lo cierto es que la naturaleza es una y la misma para todos", dice allí Spinoza desmantelando la pespectiva que adjudica las virtudes a los nobles y los vicios a la plebe. "Sin embargo", continúa, "nos dejamos engañar por el poder y la cultura, y de ahí que digamos a menudo, ante dos que hacen lo mismo, que éste lo puede hacer impunemente y aquél no; no porque sea distinta la acción, sino quien la ejecuta... Finalmente, que la plebe carece en absoluto de verdad y de juicio, no es nada extraño, cuando los principales asuntos del Estado se tratan a sus espaldas y ella no puede sino hacer conjeturas por los escasos datos que no se pueden ocultar. .. Pretender, pues, hacerlo todo a ocultas de los ciudadanos y que éstos no lo vean con malos ojos ni lo interpreten todo torcidamente, es una necedad supina. Ya que, si la plebe fuera capaz de dominarse y suspender su juicio sobre los asuntos poco conocidos, o de juzgar correctamente las cosas por los pocos datos de los que dispone, está claro que sería digna de gobernar, más que de ser gobernada” (Spinoza, 1986a, pp. 158-159). 
por la nobleza y los miembros de las corporaciones. Es el pueblo así concebido quien está legítimamente llamado a volverse contra el tirano, puesto que reúne las condiciones para gobernarse a sí mismo. En estos textos, dice Marilena, la característica es "la concepción romana de populus como conjunto de los optimates y honestiores contrapuesto al conjunto de los humiliores, esto es, la plebs". (Ibid., p. 75)

Por relación a este contexto y a esta historia de textos políticos (inscriptos en la antigua tradición del Buen Gobierno) que tuvieron su importancia en la "Siete Provincias del Norte", el Tratado político, en sintonía, nuevamente, con las Instituciones políticas libres, revela toda su singularidad y su anomalía, extendiendo la subjetividad política a grupos sociales que hasta entonces no contaban, e invocando la necesidad de un gobierno institucional contra la inestabilidad de la virtud. Spinoza parece hacer una referencia ya sea al Acta de destitución ya sea al Documento de Antuerpia, cuando en el capítulo XVIII del Tratado teológico político escribe:

Pues los prepotentes Estados de Holanda, como ellos mismos lo ponen de manifiesto en el informe publicado en tiempos del conde de Leicester, siempre se han reservado la autoridad de amonestar a dichos condes sobre sus deberes, así como el poder para defender esa autoridad suya y la libertad de los ciudadanos, para vengarse de ellos, si degeneran en tiranos y para controlarlos de tal suerte que no pudiesen hacer nada sin la aprobación y el beneplácito de dichos Estados ${ }^{17}$. (Spinoza, 1986b, p. 390).

\section{Resulta plausible que Spinoza haya podido conocer y discutir}

17 Por lo demás, tanto en el Tratado teológico político (cap. XVII y XVIII) como en el Tratado político (cap. V, 7 y cap. VIII, 9) se considera ineficaz el tiranicidio, aunque según un argumento que da la impresión de ser condicional: si subsisten las causas que engendraron al tirano, parece decir Spinoza, es inútil eliminar al tirano, pues sólo se logrará "cambiar muchas veces de tirano, mas nunca suprimirlo..." (Spinoza, 1986b, p. 389), o bien: "Maquiavelo... buscaba probar cuán imprudentemente intentan muchos quitar de en medio a un tirano, cuando no se suprimen las causas por las que un príncipe es tirano..." (Id. 1986a, V, 7). 
estos textos en el círculo de Van den Enden, quien "en 1650", dice Wim Klever "publicó bajo su propio nombre un folleto con el título de Korte Verthooninghe, que de hecho es la disertación , cuya fecha originaria es de 1585 , en la que los Estados de Holanda defendían sus derechos democráticos contra el tirano de España, rey Felipe II" (Klever,1993, p. 618). En cualquier caso, la "ciencia de los afectos" con la que la Ética y el Tratado político dotan a las instituciones democráticas de una base realista, encuentra asimismo en las últimas páginas de Instituciones políticas libres una probable inspiración; el maestro libertino escribe allí que "ningún humano (siendo como es) puede comportarse de un modo diferente de aquel en que lo hace" (Van den Enden, 2010, pp. 119-120), y transcribe in extenso un poema del polígrafo holandés P. C. Hooft. La ignorancia de que todas las acciones humanas dependen de Dios es el origen del mayor error que concierne a la política y el gobierno de los hombres, y de ella deriva la ignorancia subsidiaria de la naturaleza de las pasiones cuya manifestación se inscribe en un orden necesario de todas las cosas. Una organización democrática y libre nunca exige nada contra la Naturaleza; antes bien "deberíamos no intentar distorsionar, con nuestro liviano cuidado, la Naturaleza que halla su determinación en todas las cosas particulares, sino confiar en ella, incluso al máximo" (Ibid., p. 122), y al mismo tiempo implementar, por medio de la educación civil y contra todo espíritu de secta, un "sentimiento e interés por el Estado" - conforme una expresión que se toma prestada de Pieter de la Court.

La comunidad entre Spinoza y Van den Enden acerca de una democracia cuyas instituciones consideran las pasiones humanas como punto de partida, aloja sin embargo una querella en torno a un nombre propio: Maquiavelo. No obstante ser considerado "a menudo un muy agudo juez [expresión semejante a la que utilizará Spinoza en el Tratado político: acutissimus Florentinus] y observador en asuntos políticos" (Ibid., p. 113), el Secretario florentino, asociado a Polibio en más de una ocasión, es acusado 
por Van den Enden de impostura, de identificar gobierno y dominación, de engañar al pueblo y de no tener interés ninguno en el bien común ni en la libertad igualitaria. En el comienzo del Tratado político se adjudicará a los "políticos" (politici) este arte de tender trampas y engañar al pueblo siguiendo artilugios "cuya eficacia ha mostrado una larga experiencia”, pero algunas páginas más adelante Spinoza deja claro que Maquiavelo mismo se encuentra fuera esta consideración y realiza de él dos elogios explícitos y muy precisos [en Tratado político, 5, $\$ 7$ y 10, $\$ 1$ de la edición latina (Opera posthuma), aunque cuidadosamente suprimidos de la edición holandesa (Nagelate Schriften) $]^{18}$.

La introducción de Maquiavelo en la discusión holandesa tiene sus impulsores más importantes en los hermanos De la Court y en el propio Van den Enden, probablemente la fuente principal en la recepción spinociana del "agudísimo florentino" - cuyas obras, por lo demás, constaban en la biblioteca notariada tras la muerte del filósofo -, aunque para el autor del Tratado político Maquiavelo era "favorable a la libertad e incluso dio atinadísimos consejos para defenderla” (Spinoza, 1986a, 5, \$7). Lejos de considerarlo como un manual para tiranos, la lectura spinozista de El Príncipe (inscripta en una tradición que encuentra más bien en él un desenmascaramiento del poder al servicio de la causa popular) le adjudica el propósito de revelar con minucia precisamente aquello que los poderosos buscan siempre mantener oculto, de manera que su sentido último no es otro que el de probar "con qué cuidado debe guardarse la multitud de confiar su salvación a uno solo". Pero además, el nombre de Maquiavelo se halla asociado a una palabra central en el spinozismo, que dota

18 Wim Klever propone una interpretación diferente, pues "en acuerdo con su maestro y no menos que él”, Spinoza se opondría a la concepción maquiaveliana del gobierno mixto, en favor de un gobierno radical-democrático que excluye toda jerarquía; su propósito en ese trabajo es mostrar el "malentendido" que se halla a la base de la interpretación que considera a Spinoza un "admirador incondicional" de Maquiavelo (Klever, 2002). 
a su radicalismo filosófico y político con algo de lo que carecían otros autores que le eran contiguos, como su amigo Koerbagh, y el propio Van den Enden; esa palabra es prudencia. En efecto, "prudencia", escribe Spinoza, "no es una obediencia (sane cautio non obsequium), es al contrario la libertad de la naturaleza humana” (Ibid., IV, $\$ 5$ ).

En su Introducción a la versión francesa del Tratado político (Spinoza, 2002), Laurent Bove afirma el vínculo entre la recepción de Maquiavelo y la concepción spinozista de la conservación de los cuerpos. El imperativo de prudencia inscripto en la "necesidad de las cosas", remite en Spinoza a una exigencia vital e inmanente a las relaciones de fuerza de las potencias mismas: el imperativo ontológico de la duración. Así, la virtú maquiaveliano-spinozista es la afirmación de la potencia de actuar. No es sólo - ni fundamentalmente - el arte prudencial de elegir los medios apropiados para la consecución de un fin (por ejemplo la toma del poder y su conservación - esto sería más bien arte de la astucia, estratagema, ardid, habilidad...) según la lección de los políticos "maquiavélicos" a los que alude Spinoza en la apertura del Tratado político.

Por el contrario - siguiendo siempre a Bove -, la virtú propiamente maquiaveliana es la necesidad misma de la potencia, y es esta la lección del "prudentísimo" maestro florentino adoptada por Spinoza, quien concibe el TP como una suerte de reescritura democrática y popular del Príncipe, a partir de su propia línea filosófica de inmanencia. La operatoria spinozista sería pues la de una "radicalización de Maquiavelo" tanto en el plano ontológico como institucional, de modo que la cuestión del arte político y la conservación del Estado se inscribe en la ontología de una afirmación absoluta de la potencia de los cuerpos. El "realismo ontológico de la duración”, en suma, realiza y radicaliza la preocupación maquiaveliana de la duración.

El nombre de Maquiavelo aloja un litigio que no es menor para comprender la diferencia entre el materialismo spinozista de 
la "multitud" y la Asamblea popular vanendeniana. Si nada induce a pensar que el autor de las Proposiciones políticas libres piense al mundo social como un conjunto de fuerzas en conflicto ni por tanto se proponga el cometido de registrarlas, Spinoza - que sí lo hace- piensa el conflicto en contigüidad con las instituciones que lo dotan de una conversación. Potentia multitudinis y "experiencia política”, es decir común ejercicio de la facultad de juzgar - establecen los términos que componen el spinozismo político: Van den Enden con Maquiavelo.

Finalmente, quisiera volver sobre la autodesignación de Van den Enden a continuación del título de su libro Proposiciones políticas libres..., concebidas - se lee - por "quien, por el bien común, más ama las cosas". El vínculo entre el amor de las cosas y la indagación del bien común no revela inmediatamente su pertinencia ni su significado real, aunque tal vez un sentido oculto obtiene explicitación si consideramos que ese amor es intelectual y componemos el pequeño sintagma vanendeniano con algunas líneas de Ética V. Amor de las cosas y búsqueda del bien común: no una cosa junto a la otra sino una cosa por la otra, a causa de la otra. Cuanto más entendemos las res singulares, escribe Spinoza, más entendemos a Dios (Ética, V, 24) y de ese entendimiento surge el amor intelectual (Ética, V, 32, corol.), por lo que el amor a Dios se incrementa de manera proporcional al amor de las cosas singulares -en rigor no tendríamos cómo distinguir uno de otro. De allí la circularidad de la expresión spinozista según la cual "el amor de Dios a los hombres y el amor intelectual del alma a Dios es una y la misma cosa" (Ética, V, 36, corol.).

Si ponemos la expresión: "quien, por el bien común, más ama las cosas" bajo el prisma de Ética V, se explicita el vínculo encriptado entre amor (intelectual) de las cosas (amor homines erga Deum) y democracia radical en tanto irrupción del bien más "común" (amor Dei erga homines); democracia pues en tanto comunismo inherente a la expresión amor Dei intellectualis. Quien por el bien común más ama las cosas, conjunta democracia y fi- 
losofía con una intensidad que nunca antes había tenido y muy pocas veces tendrá después, en la singularidad de una experiencia que revela el contenido filosófico de la democracia y, a la vez, el contenido democrático de la filosofía.

Referências bibliográficas

BEJDAÏ, M. "Franciscus van den Enden. Maître spiritual de Spinoza”, Revue de l' Histoire des Religions, n. 207, 1990a, pp. 289-311.

. "Métaphysique, éthique et politique dans l'oeuvre de Docteur Franciscus van den Enden. Contribution à l'étude des sources des écrits de B. de Spinoza", Studia Spinozana, 6, 199ob, pp. 291-313.

. "Pour un État populaire ou une utopie subversive". Amsterdam XVII siècle. Marchands et philosophes: les bénéfices de la tolérance. Paris: Éditions Autrement, 1993, pp. 194-213.

BELTRÁN, M. Un espejo extraviado. Spinoza y la filosofía hispano-judía. Barcelona: Riopiedras, 1998.

CHAUI, M. "La plebe y el vulgo en el Tractatus Politicus", AA.VV., Coloquio Internacional Spinoza, Dolmen, Santiago de Chile, 1990, pp. 69-95.

ESPINOSA, B. Traité politique. Trad. Émile Saisset. Paris: Librairie Générale Française, 2002.

. Tratado político. Trad. Atilano Domínguez. Madrid: Alianza, 1986a.

Tratado teológico político. Trad. Atilano Domínguez. Madrid: Alianza, 1986b.

FRANCÈS, M. Spinoza dans les pays néerlandais de la seconde moitié du XVII siècle. Paris: Alcan, 1937.

ISRAEL, J. Les lumières radicales. La philosophie, Spinoza et la naissance de la modernité (1650-1750). Paris: Éditions Amsterdam, 2005.

KLEVER, W. "Proto-Spinoza Franciscus van den Enden", Studia Spinozana, n. 6, 1990, pp. 281-291. 
"A New Source of Spinozism: Franciscus van den Enden", Journal of the History of Philosophy. n. 29, 1993, pp. $613-633$.

"Imperium aeternum. Spinoza's critique of Machiavelli and its sources in Van den Enden”, Foglio spinozi@ no, 14, 2002.

MEINSMA, K. O. Spinoza et son cercle. Étude critique historique sur les hétérodoxes hollandais. Paris: Vrin, 2006.

MERTENS, F. http://users.telenet.be/fvde/

PROIETTI, O. Philedonius, 1657: Spinoza, Van den Enden e i classici latini. Macerata: Edizioni Università di Macerata, 2010. ROCHA, M.; NOGUEIRA, D. "Franciscus van den Enden (16021674) - Ex-jesuíta, poeta, médico, comerciante de arte, filósofo e político, professor de Spinoza, encenador de comedias latinas, conspirador contra Luís XIV...”. In: TATIÁN, D. (org.), Spinoza. Sexto coloquio, Brujas, Córdoba, 2010, pp. 33-42.

VAN DEN ENDEN, F. Libertad política y Estado. Trad. Leandro García Ponzo. Buenos Aires: El cuenco de plata, 2010. Vrije Politijke Stellingen. Amsterdam: Wereldbibliotheek, 1992. 
